\title{
Mediterranean Spotted Fever with an Acute Pancreatitis
}

Mouna ELFane*, Mustapha Sodqi, Sanae Jebbar, Hanane Badi, Latifa Marih, Abdelfattah Chakib and Kamal Marhoum EIFilali

Department of Infectious Diseases, UHC Ibn Rochd, Casablanca, Morocco

*Corresponding author: Mouna ELFane, Department of Infectious Diseases, UHC Ibn Rochd, Casablanca, Morocco, Tel: 212 660832362; E-mail: elfanemouna@gmail.com

Received date: October 17, 2016; Accepted date: November 14, 2016; Published date: November 21, 2016

Copyright: $\odot 2016$ ELFane M, et al. This is an open-access article distributed under the terms of the Creative Commons Attribution License, which permits unrestricted use, distribution, and reproduction in any medium, provided the original author and source are credited.

\begin{abstract}
Mediterranean spotted fever (MSF) is a tick-borne acute febrile disease caused by Rickettsia conorii characterized by fever, maculo-papular rash and a black eschar at the site of the tick bite (tache noire). Acute pancreatitis is a rare complication of MSF. We report a 45 year old man admitted with fever, maculopapular rash, and eschar (tache noire). The working diagnosis at admission was MSF. Five day after admission, the patient developed signs of an acute abdomen, amylase and lipase elevation, and ultrasound hypoechoic pancreas. CT scan revealed a stage B pancreatitis. An immunofluorescence antibody test confirmed Rickettsia conorii infection. Diagnosis of MSF was made and treatment with oral doxycycline was started. After five days of therapy, there was completed remission of epigastric pain and fever. Gastrointestinal and hepatic complications are described in association with MSF. Much rarer is pancreatic involvement. Inflammation may play a role in the pathogenesis of pancreatitis. This suggests that pancreas should be explored in MSF patients even in the absence of underlying risk factors.
\end{abstract}

Keywords: Mediterranean spotted fever; Rickettsia conorii; Pancreatitis

\section{Introduction}

Mediterranean spotted fever (MSF) is a rickettsial disease caused by Rickettsia conorii endemic for countries along the Mediterranean coast (South Europe and North Africa) [1-3]. The vector of the infection is the brown dog tick Ripicephalus sanguineus, wich is widespread in the Mediterranean area during the favorable for tick's biology springsummer season. MSF is typically characterized by fever, maculopapular rash and a black eschar at the site of the tick bite ('tache noire'). MSF has long been considered a benign disease [4]. However, severe forms of the disease with major morbidity and higher mortality risk have been described. Complications are described mainly in adult patients and include hepatic, renal and cardiac impairment. Among gastrointestinal complications, pancreatitis has been reported rarely [5]. We described the case of a 45 year old man affected by MSF who developed acute pancreatitis.

\section{Case Report}

A previously healthy 45 year-old man, resident in an urban environment was admitted to unit of infectious disease with a six-day history of fever $\left(39^{\circ} \mathrm{C}\right)$, myalgia, nausea, and cutaneous rash, complicated by vomiting and upper abdominal pain. On the admission, patient was in acute distress with body temperature of 39 , pulse rate of 110 beats/min, respiratory rate of $30 / \mathrm{min}$ and blood pressure 100/60 $\mathrm{mm} \mathrm{Hg}$. Physical examination revealed diffuse maculopapular rash over the anterior chest, lower extremities and palmoplantar regions, and eschar (Figure 1) over the thigh were observed. The abdomen was ovoid in shape. Bowel sound was hypoactive; the liver and the spleen were not palpable. The leukocytes count was $12000 / \mathrm{mm}^{3}$, with $70 \%$ neutrophil. The level of hemoglobin, platelet and CRP were $12 \mathrm{~g} / \mathrm{dl}, 80000 / \mathrm{mm}^{3}$, and $75 \mathrm{~g} / \mathrm{L}$, respectively.

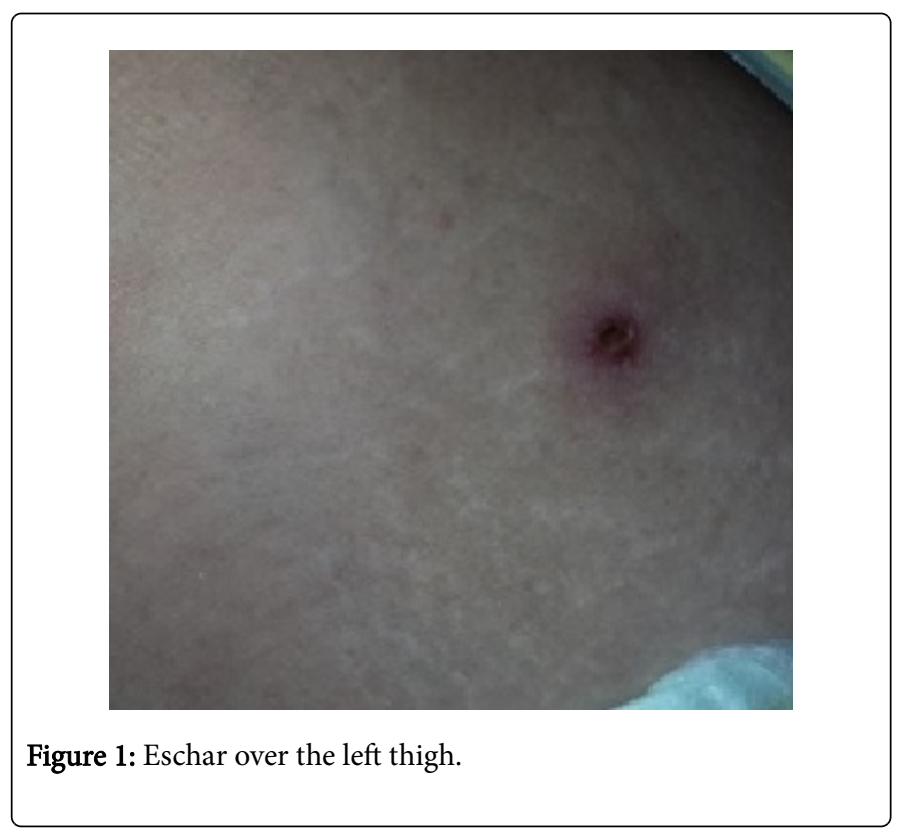

Prothrombin and partial thromboplastin time were normals. Serum liver, renal and pancreatic profiles were as follow: total bilirubin 24 $\mathrm{mg} / \mathrm{L}$; aspartate aminotransferase $161 \mathrm{U} / \mathrm{L}$ (normally less than $40 \mathrm{U} / \mathrm{L}$ ); alanine aminotransferase $107 \mathrm{U} / \mathrm{L}$ (normally less than $40 \mathrm{U} / \mathrm{L}$ ); albumin $3.9 \mathrm{~g} / \mathrm{dl}$ (normally 3.5-5.1 g/ dL); amylase $108 \mathrm{U} / \mathrm{L}$ (normally 28-160 U/L); lipase $783 \mathrm{U} / \mathrm{L}$ (normally 0-60 U/L); creatinine $4.5 \mathrm{mg} / \mathrm{dl}$ (normally $0.5-1.4 \mathrm{mg} / \mathrm{dl}$ ). Serology test for Rickettsia conorii turned out positive on the 13 day. Abdominal CT showed mild edematous pancreas with peripancreatic infiltration (Figure 2). Based on the confirmation of MSF with pancreatitis, therapy was performed with oral doxycycline daily administered orally in the amount of $200 \mathrm{mg} /$ day. The patient's lung and kidney conditions improved markedly four 
weeks later. On the seventh-day, the abdominal pain and fever disappeared, and the general condition was also improved. At complete recovery, serum level of lipase decreased to normal level. He was discharged on the $14^{\text {th }}$ day. On the $29^{\text {th }}$ day after the discharge, followup abdominal CT scan showed complete resolved pancreatic edema and per-pancreatic infiltrations.

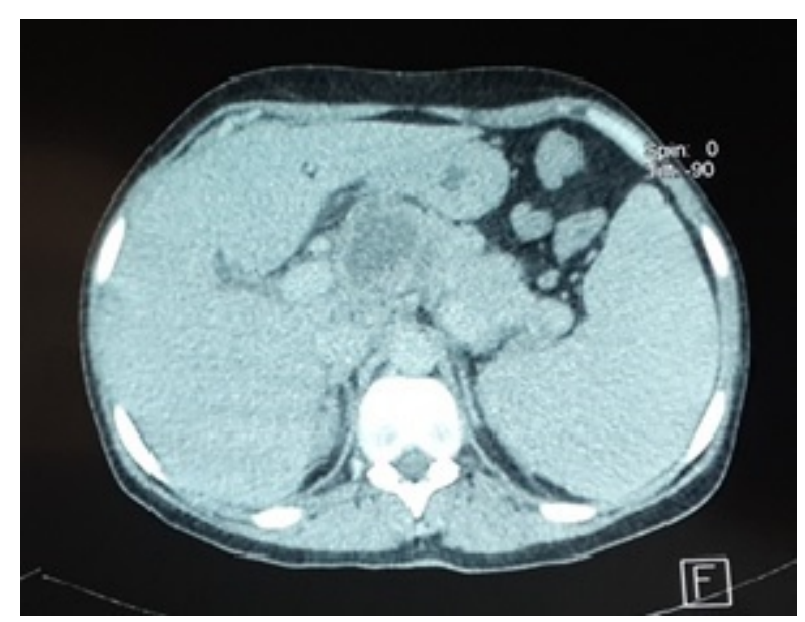

Figure 2: CT abdomen showing pancreatic infiltration.

\section{Discussion}

Clinically MSF is characterized by a generalized vasculitis process with the classic clinical triad of fever, rash and skin eschar at the site of the tick bite (tache noire) [6]. Rash appears 5-7 days after onset of symptoms. Rash can be macular, maculopapular, petechial or hemorrhagic [7]. Eschar can be single or multiple or may not be seen in some cases [8]. Although the majority of cases are considered benign, in the past years severe forms of MSF have emerged, requiring intensive care facilities [9]. In the early 1980s, Raoult reported a patient with a fatal outcome due to MSF and used the term malignant for the most severe forms of the disease [10]. Reported severe complications of MSF include pneumonitis, acute renal failure, acute respiratory distress syndrome, myocarditis, and septic shock [11]. Abdominal involvement is unusual in MSF. Gastrointestinal symptoms including nausea, vomiting, and anorexia are prominent and potentially confusing diagnostically. They may even mimic a surgical abdomen, leading to an erroneous diagnosis of an acute abdomen [12]. Gastrointestinal manifestations are present more frequently than rash during the first 2-3 days of illness. The classical described tetrad of fever, headache, rash, and a history of tick bite is rarely encountered at this stage of the illness [12]. Hepatic injury manifests as increased aminotransferase levels and occasional jaundice [7]. It is a predictor of mortality and is likely the result of a combination of inflammatory bile ductular obstruction and hemolysis [12]. Hepatosplenomegaly and generalized lymphadenopathy may be seen [13]. Acute pancreatitis is, however, very rare and potentially fatal [12]. In a review of literature few reports on acute pancreatitis in rickettsiosis are found [14]. Recently, Ivan Baltadzhieva et al. in Bulgaria reported 4 cases of MSF with acute pancreatitis [15]. In our case, acute pancreatitis was related to MSF for several reasons, including a history of tick contact and eschar, summer incidence, fever, and characteristic rash. In addition, other data provided evidence for the diagnosis as follows: positive serologic test finding, progressive increase of lipasemia. The diagnosis of pancreatitis is based on elevated pancreatic enzymes and imaging. Serum lipase has a higher sensitivity and specificity up to $82-100 \%$. In addition, lipase level peaks early and lasts longer, returning to normal after about six to eight days only [16]. Abdominal TC scan is the gold standard technique for diagnosis of acute pancreatitis, to confirm diagnosis, to exclude alternative diagnoses and to determine the severity and presence of complications [17].

Clinical clue to the diagnosis depends on epidemiology, characteristic rash, eschar and investigations showing normal or low leucocytes count, thrombocytopenia, hyponatraemia, and elevated transaminases levels [18]. Immunofluorescence assay is the recommended diagnostic test. Weil-Felix test has low sensitivity and hence is not recommended as a diagnostic test.

Polymerase chain reaction, immunohistochemistry and isolation of the organism in cell culture, are other useful investigations [18]. The main pathologic lesion of MSF is vasculitis with ischemic necrosis [12]. Rickettsial vasculitis process of injury in the upper gastrointestinal tract is histologically similar to that observed in other organs in patients with MSF and may manifests clinically by digestive tract bleeding [3]. Randall and al founded lesions in pancreatic tissue in $91 \%$ of cases and in tissue obtained from the stomach, small intestine, and colon in all cases. Most tissues were judged to be only moderately injured [19]. Doxycycline is the drug of choice for MSF. Josamycin or chloramphenicol is recommended in pregnancy. Other useful drugs include azithromycin, clarithromycin and ciprofloxacin. Treatment should be initiated as early as possible, on clinical suspicion alone to prevent a bad outcome, because confirmed diagnosis is made in routine clinical practice by IFA which is positive in the second week of illness [18].

In conclusion, we report a MSF case complicated by acute pancreatitis. Health practitioners in endemic areas should be aware of unusual medical causes of acute abdomen namely, MSF and pancreas should be explored in MSF patients even in the absence of underlying risk factors.

\section{References}

1. Rovery C, Brouqui P, Raoult D (2008) Questions on Mediterranean spotted fever a century after its discovery. Emerg Infect Dis 14: 1360-1367.

2. Parola P, Paddock CD, Socolovschi C, Labruna MB, Mediannikov O, et al. (2013) Update on tick-borne rickettsioses around the world: a geographic approach. Clin Microbiol Rev 26: 657-702.

3. França Pereira M, Romãozinho J, Sofia C (2013) Mediterranean spotted fever with involvement of the gastrointestinal tract. BMJ Case Rep.

4. Baltadzhiev I, Popivanova N, Zaprianov Z (2016) Clinical and Laboratory Prognostic Factors in Malignant form of Mediterranean Spotted Fever. International Journal of Pharmaceutical Invention 5: 1-6.

5. Walker D, Lesesne H, Varma V, Thacker W (1985) Rocky Mountain Spotted Fever Mimicking Acute Cholecystitis. Arch Intern Med 145: 2194-2196.

6. Sousa R, Nóbrega SD, Bacellar F, Torgal J (2003) Epidemiologic features of Mediterranean spotted fever in Portugal. Acta Med Port 16: 429-436.

7. Joshi HS, Mathew T, Warrier A, Suresh K (2012) Gangrene in cases of spotted fever: a report of three cases. BMJ Case Reports.

8. Murali N, Pillai S, Cherian T, Raghupathy P, Padmini V, et al. (2001) Rickettsial infections in South India-how to spot a spotted fever. Indian Pediatr 38: 1393-1396. 
Citation: ELFane M, Sodqi M, Jebbar S, Badi H, Marih L, et al. (2016) Mediterranean Spotted Fever with an Acute Pancreatitis. J Antimicrob Agents 2: 129. doi:10.4172/2472-1212.1000129

Page 3 of 3

9. Amaro M, Bacellar F, França A (2003) Report of eight cases of fatal and severe Mediterranean spotted fever in Portugal. Ann NY Acad Sci 990: 331-343.

10. Raoult D, Gallais H, Ottomani A, Resch JP, Tichadou D, et al. (1983) Malignant form of Mediterranean boutonneuse fever. 6 cases. Presse Med 12: $2375-2378$.

11. Yi SY, Tae JH (2007) Pancreatic abscess following scrub typhus associated with multiorgan failure. World J Gastroenterol 13: 3523-3525.

12. Zaidi SA, Singer C (2002) Gastrointestinal and Hepatic Manifestations of Tickborne Diseases in the United States. Clin Infect Dis 34: 1206-1212.

13. Sirisanthana V, Puthanakit T, Sirisanthana T (2003) Epidemiologic, clinical and laboratory features of scrub typhus in thirty Thai children. Pediatric Infect Dis 22: 341-345.

14. Ferreira M, Coelho R, Luzio J, Coutinho P (2008) Increased lipase and amilase levels in critically ill patients. Retrospective study. Rev Bras Ter Intensiva 20: 362-369.
15. Baltadzhiev I, Popivanova N, Zaprianov Z (2016) Malignant forms of Mediterranean spotted fever: risk factors for fatal outcomes. Braz J Infect Dis.

16. Iqbal A, Kundavaram AP, Sathyendra S, Ooriapadickal CA (2014) Pancreatitis due to Scrub Typhus. J Glob Infect Dis 6: 31-34.

17. Forsmark CE, Baillie J (2007) AGA Institute technical review on acute pancreatitis. Gastroenterology 132: 2022-2044.

18. Fauci AS, Braunwald E, Kasper DL (2008) Harrisons's principles of internal medicine. 7th edn New York: Mc Graw Hill Publication: 1059-1067.

19. Randall MB, Walker DH (1984) Rocky Mountain spotted fever. Gastrointestinal and pancreatic lesions and rickettsial infection. Arch Pathol Lab Med 108: 963-967. 